\title{
PENGARUH PENDEKATAN CONTEXTUAL TEACHING AND LEARNING (CTL) TERHADAP MOTIVASI DAN HASIL BELAJAR PAI SISWA SMPN 1 SASAK RANAH PASISIE
}

\author{
Petriani $^{1}$, Mahyudin Ritonga ${ }^{2}$, Ahmad Lahmi $^{3}$ \\ ${ }^{1}$ Program Studi Pendidikan Agama Islam, Program Pascasarjana, Universitas \\ Muhammadiyah Sumatera Barat \\ ${ }^{2}$ Program Studi Pendidikan Bahasa Arab, Fakultas Agama Islam, Universitas \\ Muhammadiyah Sumatera Barat \\ ${ }^{3}$ Program Studi Pendidikan Agama Islam, Fakultas Agama Islam, Universitas \\ Muhammadiyah Sumatera Barat \\ *petriani@gmail.com \\ *mahyudinritonga@gmail.com
}

\begin{abstract}
ABSTRAK
Riset ini bertujuan untuk mengukur pengaruh pendekatan CTL terhadap : 1)motivasi siswa 2) hasil belajar pada pembelajaran PAI di kelas VIII 3 SMP Negeri 1Sasak Ranah Pasisie, Pasaman Barat. Adapun jenis riset ini adalah kuantitatif deskriptif. Sampel riset ini siswa Kelas VIII ${ }_{3}$ SMPN1Sasak Ranah Pasisie yang berjumlah 33 orang. Sampel tersebut diambil berdasarkan pada teknik purposive sampling. Data dianalisis secara statistik menggunakan model regresi korelasi. Hasil dari analisis data memperlihatkan : 1) pendekatan CTL memiliki hubungan yang signifikan dengan motivasi belajar yang dibuktikan oleh nilai $r_{\text {hitung }}(0,760)>r_{\text {tabel }}(0,296)$ pada signifikansi 0.05 , dan $r_{\text {hitung }}$ $(0,760)>r_{\text {tabel }}(0,4093)$ pada signifikansi 0.01, dan antara pendekatan CTL dengan hasil belajar dengan nilai $r_{\text {hitung }}(0,753)>r_{\text {tabel }}(0,296)$ pada signifikansi 0.05 , dan kemudian uji regresi sebesar $30 \%$ dengan $R$ Square adalah 0.303. 2) Terdapat pengaruh pendekatan CTL terhadap hasil belajar terlihat dari hasil d $r_{\text {hitung }}(0,753)>r_{\text {tabel }}(0,296)$ di taraf 0.05 , dan $r_{\text {hitung }}(0,753)>r_{\text {tabel }}(0,4093)$ pada signifikansi 0.01, sebesar 50\% dengan $R$ Square adalah 0.509 .
\end{abstract}

Kata Kunci: Pendekatan CTL, Motivasi, Hasil Belajar

\begin{abstract}
This research aims to measure the effect of the Contextual Teaching and Learning (CTL) approach on: 1) student motivation 2) learning outcomes in PAI learning in class VIII 3 Middle School 1 Sasak Ranah Pasisie, West Pasaman. This type of research is quantitative descriptive. The research sample was 33 students in Class VIII 3 of SMP State 1 Sasak Ranah Pasisie, amounting to 33 people. The sample was taken based on purposive sampling technique. Data were analyzed statistically using the correlation regression model. The results of this research data analysis show that: 1) there is a significant relationship between the CTL approach and learning motivation as evidenced by the value of $r$ count $(0.760)>$ rtable (0.296) at a significance of 0.05, and rcount (0.760)> rtable (0.4093) at a significance of 0.01, and between the CTL approach and learning outcomes with a calculated value (0.753)> rtable (0.296) at a significance of 0.05 , and then a regression test of $30 \%$ with $R$ Square is 0.303. 2) There is an effect of the CTL approach to learning outcomes as evidenced by rcount (0.753)> rtable (0.296) at the 0.05 significance, and rcount $(0.753)>$ rtable $(0.4093)$ at a 0.01 significance, at $50 \%$ with $R$ Square being 0.509 .
\end{abstract}

Keywords: CTL Approach, Motivation, Learning Outcomes 


\section{PENDAHULUAN}

Kualitas Pembelajaran menjadi bagian penting dalam menentukan kualitas pendidikan (Nurjanah \& Sofiawati, 2019), (Panggabean \& Himawan, 2016). Peningkatan kualitas pembelajaran menjadi hal yang utama dalam peningkatan kualitas pendidikan. Kegiatan pembelajaran menunjukkan adanyaketerkaitan antara peserta didik dengan sumber belajar dan lingkungan. Proses ini bertujuan agar peserta didik memperoleh pengetahuan dan keterampilan baru (Zamroni, 2019).

Dalam mengajarkan pengetahuan, Allah menggunakan metode agar nabi Adam mengenal semua nama dari ciptaan Allah (QS: 2, 31). Berkaitan dengan ayat tersebut Rasul mengatakan

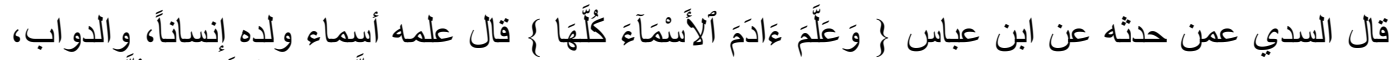

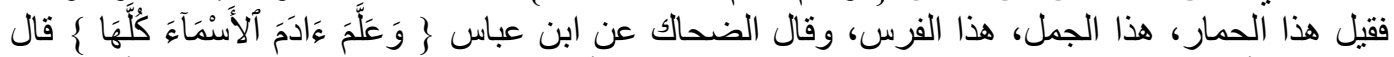

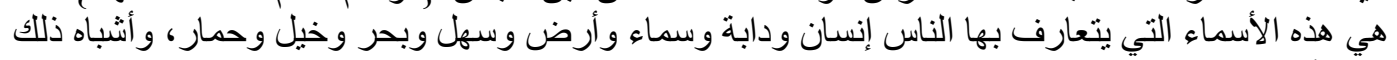

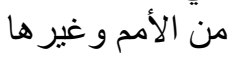

Artinya: As-Saddi berkata tentang orang yang menceritakan kepadanya dari ibn "Abbas " berkaitan dengan firman Allah yang berati " Allah mengajarkan Nabi Adam tentang nama-nama semua yang ada di alam ini, dia berkata Allah mengajarkan semua nama keturunan nabi adam, binatang melata, maka ada yang mengatakan ini keledai, ini unta, ini kuda dan sebagainya. Ad-Dahhak mengatakan dari ibn Abbas tentang maksud dari firman Allah “ Dia mengajarkan adam tentang nama-nama semuanya, ini adalah namanama yang dikenal oleh manusia, binatang, nama-nama di langit dan di bumi, darat dan lautan, kuda, keledai dan nama-nama makhluk yang lainnya.

Hadis ini menjelaskan bahwa dalam mengajarkan pengetahuan kepada nabi Adam, Allah SWT menggunakan metode tertentu, dalam hadis ini digambarkan bahwa Allah menyebutkan nama sesuatu dengan langsung menunjukkan bendanya. metode ini sesuai dengan metode CTL.

Penggunaan metode tertentu sebagaimana diungkapkan oleh para ahli berpengaruh positif terhadap hasil belajar peserta didik (Hakim \& Ritonga, 2018), (Raman, Haniffa, \& Haron, 2018), motivasi (Asvio, Arpinus, \& Suharmon, 2017), suasana dan sikap belajar (Sen, 2013).

Sejalan dengan beberapa hasil penelitian di atas, untuk mata pelajaran PAI di SMPN 1 Sasak Ranah Pasisie, peserta didik belum memperoleh hasil yang optimal. Hipotesis peneliti dalam hal ini adalah dipengaruhi oleh pendekatan yang digunakan guru dalam mengajarkan PAI, guru terbatas pada metode tradisional yakni metode ceramah. Penggunaan metode tersebut juga mempengaruhi motivasi peserta didik dalam mengikuti pelajaran PAI, sehingga tidak jarang di antara peserta didik yang disibukkan dengan keluar-masuk kelas.

Konsekuensi logis dari motivasi siswa yang rendah membuat hasil belajar juga belum sesuai dengan yang diharapkan. Namun dasarnya juga dikembalikan kepada guru, yakni bagaiman guru memilih dan menggunakan pendekatan yang tepat. Sejalan dengan realita di atas peneliti ingin melakukan riset yang berkaitan dengan penggunaan CTL dan mengetahui pengunaan metode ini dan pengaruhnya 
terhadap motivasi dan hasil belajar PendidikanAgama Islam di SMPN 1 Sasak Ranah Pasisie.

Pembelajaran kontekstual merupakan pembelajaran yang mampu menjadikan peserta didik mengetahui keterkaitan materi pembelajaran dengan realita dalam keseharian mereka (Manangkari, 2018). Konsep CTL membawa guru menemukan keterkaitan materi pembelajaran dengan kenyataan (Sufianto, 2019). Peran utama guru dalam pembelajaran adalah tujuan pembelajaran bisa tercapai. Dengan mengunakan CTL yang menggunakan konsep pembelajaran bermakna peserta didik akan lebih mampu menyerap materi pembelajaran (Haryanto \& Arty, 2019), (Kosassy, Gistituati, Jama, \& Montessori, 2018). Dengan pembelajaran kontekstual memberikan pengalaman penting bagi peserta didik menemukan keterkaitan pelajaran akademis dengan kehidupan nyata.

Pembelajaran dengan konsep CTL, berperan membantu peserta didik mengambil arti dari materi pembelajaran yang dipelajari dengan jalan mencari keterkaitan antar subjek pembelajaran dengan kondisi pribadi, sosial dan budaya mereka.

Menurut Munaroh terdapat tiga pilar dalam Contextual Teaching Learning (Munawaroh \& Setyani, 2015), pertama, dalam CTL terdapat prinsip kesalingbergantungan. Prinsip ini tampak jelas ketika para peserta didik bekerjasama dalam menyelesaiakan persoalan. Ketika terbentuk kerjasama antara sekolah dan dunia bisnis. Kedua menunjukkan prinsip diferensiasi. Pada prinsip ini pesert didik diarahkan agar memahami bahwa keberagaman dalam ide dan gagasan menjadi tanda kemantapan dan kekuatan. Peserta didik mampu menghargai perbedaan dan keunikan masing-masing dalam proses menjadi kreatif serta kooperatif. Ketiga CTL mencerminkan prinsip pengorganisasian diri. Dalam proses pengorganisasian diri peserta didik dibuat mampu mengenal diri mereka sendiri, memahami minat yang berbeda di antara mereka. Mampu mengambil manfaat dari proses penilaian autentik, serta menentukan indikator pencapaian tujuan yang jelas dan dengan kualitas yang bagus, sehingga membuat mereka berperan aktif dalam pembelajaran yang berpola students centre.

Terdapat lima ciri utama pada pembelajaran menggunakan pendekatan CTL yaitu: 1) terjadi pengaktifan pengetahuan yang sudah ada sebagai bagian dari proses pembelajaran (activating knowledge). 2) dengan menggunakan metode CTL proses pembelajaran menjadi usaha untuk mendapatkan dan meningkatkan ilmu pengetahuan baru (acquiring knowledge). 3) dalam CTL ilmu pengetahuan yang sudah didapatkan harus dipahami (understanding knowledge). 4) pengalaman serta ilmu pengetahuan yang didapatdiaplikasikandalamkehidupan sehari-hari. (applying knowledge). 5) Perlu dilakukan refleksi terhadap pengetahuan yang diperoleh (reflecting knowledge) Satriani, Emilia, and Gunawan 2012).

Pendidik dalam hal ini guru harus memiliki pengetahuan mengenai keinginan peserta didik terutama berkaitan dengan prestasi. Masing-masing siswa mempunyai kebutuhan yang berbeda (Sari \& Wilujeng, 2020). Fakta menunjukkan banyak peserta didik memiliki motivasi yang rendah dalam mencapai prestasi, mereka lebih cenderung untuk tidak mau mangambil resiko dan mengalami kegagalan dalam memperoleh prestasi belajar yang baik. Namun tidak sedikit peserta didik yang memiliki keinginan yang kuat untuk mencapai prestasi yang tinggi. 
Dalam dunia pendidikan, penghargaan, ketenaran, perhatian, pengakuan terhadap keberadaan peserta didik, status merupakan bagian dari kebutuhan peserta didik yang memberikan pengaruh kuat terhadap motivasi belajarnya (Wong \& Dubey-Jhaveri, 2016). Sebagai seorang guru yang berpengalaman maka seorang guru dapat memanfaatkan kebutuhan peserta didik tersebut untuk meningkatkan semangat belajar siswa agar mengikuti pembelajaran secara aktif. Jika kebutuhan mereka terpenuhi maka semangat belajar untuk mencari tahu terhadap sesuatu akan lebih meningkat. Motivasi belajar menjadi hal terpenting dalam kegiatan pembelajaran, oleh karena itu diperlukan kemampuan pendidik dalam menjaga agar peserta didik senantiasa termotivasi dalam belajar. Motivasi setiap peserta didik berbeda-beda (Riswanto \& Aryani, 2017), oleh karena itu guru juga harus paham terhadap kebutuhan motivasi peserta didik.

\section{METODOLOGI}

Penelitian ini memaparkan hasil dalam bentuk angka, sehingga merupakan penelitian kuantitatif. Penelitian dirancang dengan Regretion. Yaitu hubungan kausal yang menunjukkan pengaruh dari dua variable yang berbedaantar $X$ terhadap $\mathrm{Y}_{1}$ dan $\mathrm{Y}_{2}$.

Pada penelitian ini populasi dijadikan sampel penelitian meliputi 31 siswa, 15 orang laki-laki dan 16 perempuan. Jumlah populasi kecil dari 100 akibatnya semua anggota populasi dijadikan sampel penelitian.

Teknik menghimpun data ialah dengan menggunakan angket atau kuesioner yakni kumpulan pertanyaan maupun pernyataaan yang diajukan pada responden. Selain itu, peneliti melakukan studi dokumentasi untuk menemukan data tentang hasil belajar PAI.

Untuk mengetahui hasil penelitian, maka dilakukan beberapa analisis, yaitu:

1. Mencari Korelasi

Untuk mengetahui korelasi antar variable digunakan rumus: $\gamma x y=\frac{\Sigma_{x y}}{N \cdot S D x S D y}$.

2. Menghitung Persamaan Regresi

Nilai dari koefisien regresi dihitung dengan menggunakan rumus $\hat{Y}=a+b X$

$\hat{\mathrm{Y}}=$ Variabel Respon (Dependent)

$\mathrm{a}=$ Konstan

$\mathrm{b}=$ Kofesiensi Regresi

3. Uji F

Uji ini merupakan uji keberartian yaitu menentukan tingkat signifikansi pengaruh setiap variabel, untuk uji $\mathrm{F}$ peneliti menggunakan Uji ANOVA. Kriteria: Jika nilai $F_{\text {hitung }}>F_{\text {table }}$ maka terdapat pengaruh variable $\mathrm{X}$ terhadap variable $\mathrm{Y}$ secara berarti.

4. Uji t

Uji t, atau Uji independen, yang bertujuan menentukkan pengaruh variabel dependen terhadapa variabel independen secara terpisah, kemudian digunakan analisis korelasi parsial untuk melihat pengaruh masing-masing variable. 


\section{HASIL PENELITIAN DAN PEMBAHASAN}

Pada hasil ini akan tergambar uji korelasi antar variable $\mathrm{X}$ terhadap $\mathrm{Y} 1$ dan Y2, uji F dan uji $\mathrm{T}$, sebagaimana yang terdapatpadatabel di bawah ini.

Tabel 1. Korelasi Product Moment Pendekatan CTL (X) dengan motivasi Belajar Peserta Didik (Y1)

\begin{tabular}{|ll|l|l|}
\hline & $\mathrm{X}$ & $\mathrm{Y} 1$ \\
\hline $\mathrm{X}$ & Pearson Correlation & 1 & $.760^{* *}$ \\
& & & .000 \\
& Sig. (2-tailed) & & 31 \\
$\mathrm{~N}$ & 31 & 1 \\
\hline Y1 & Pearson Correlation & $.760^{* *}$ & \\
& Sig. (2-tailed) & .000 & \\
& $\mathrm{~N}$ & 31 & 31 \\
\hline
\end{tabular}

Tabel 2 Korelasi Product Moment Pendekatan CTL (X) dengan motivasi Belajar Peserta Didik (Y2)

\begin{tabular}{|ll|r|r|}
\hline & Correlations \\
\hline $\mathrm{X}$ & Pearson Correlation & X & Y2 \\
& Sig. (2-tailed) & 1 & $.753^{* *}$ \\
& $\mathrm{~N}$ & 31 & .000 \\
Y2 & Pearson Correlation & $.753^{* *}$ & 31 \\
& Sig. (2-tailed) & .000 & 1 \\
N & 31 & 31 \\
\hline
\end{tabular}

Tabel 3 Korelasi Product Moment dengan motivasi Belajar Peserta Didik (Y1) dengan Prestasi Belajar (Y2)

\begin{tabular}{|ll|r|r|}
\hline \multicolumn{2}{|c|}{ Correlations } \\
\hline Y1 & Y1 & Y2 \\
& Pearson Correlation & 1 & $.870^{* *}$ \\
& Sig. (2-tailed) & & .000 \\
N & 31 & 31 \\
\hline Y2 & Pearson Correlation & $.870^{* *}$ & 1 \\
& Sig. (2-tailed) & .000 & \\
& N & 31 & 31 \\
\hline
\end{tabular}




\section{UJI F}

Tabel 4 Perbandingan $\mathrm{F}_{\text {Hitung }}$ dengan $\mathrm{F}_{\text {Tabel }}$ Variabel $\mathrm{X}$ dan $\mathrm{Y} 1$

ANOVA $^{\mathrm{a}}$

\begin{tabular}{|c|c|c|c|c|c|c|}
\hline & & $\begin{array}{l}\text { Sum } \\
\text { of } \\
\text { Squares }\end{array}$ & df & $\begin{array}{l}\text { Mean } \\
\text { Square }\end{array}$ & $\mathrm{F}$ & Sig. \\
\hline \multirow[t]{3}{*}{1} & Regression & $\begin{array}{l}24258 \\
189\end{array}$ & 1 & 12129.095 & $\begin{array}{l}54.44 \\
2\end{array}$ & $.000^{\mathrm{a}}$ \\
\hline & Residual & $\begin{array}{l}15372 . \\
422\end{array}$ & 30 & 222.789 & & \\
\hline & Total & $\begin{array}{l}39630 . \\
611\end{array}$ & 31 & & & \\
\hline
\end{tabular}

a. Dependent Variable: $\mathrm{X}$

b. Predictors: (Constant), Y1

Tabel 5 Perbandingan $\mathrm{F}_{\text {Hitung }}$ dengan $\mathrm{F}_{\text {Tabel }}$ Variabel $\mathrm{X}$ dan $\mathrm{Y} 2$

ANOVA $^{a}$

\begin{tabular}{|ll|l|l|l|l|l|}
\hline Model & $\begin{array}{l}\text { Sum of } \\
\text { Squares }\end{array}$ & df & $\begin{array}{l}\text { Mean } \\
\text { Square }\end{array}$ & F & Sig. \\
\hline 1 & Reg & 21258. & 1 & 29. & 50.10 & $.000^{\mathrm{a}}$ \\
& ression & 109 & 529 & 2 & \\
& Resi & 11372. & 29 & 67. & & \\
& dual & 122 & & 631 & & \\
& Total & 3263 & 30 & & & \\
& & 0.231 & & & \\
\hline A & Dependent Variable: X & & \\
\hline B & Predictor: (Constant,) Y2
\end{tabular}

Tabel 6 Determinasi X Terhadap Y1

\begin{tabular}{|c|c|c|c|c|}
\hline \multicolumn{5}{|c|}{ Model Summary $^{\mathbf{b}}$} \\
\hline $\begin{array}{c}\text { Mo } \\
\text { del }\end{array}$ & $\mathrm{R}$ & $\mathrm{R}$ Square & $\begin{array}{c}\text { Adjusted R } \\
\text { Square }\end{array}$ & $\begin{array}{c}\text { Std. Error of the } \\
\text { Estimate }\end{array}$ \\
\hline 1 & $\begin{array}{c}.473 \\
\mathrm{a}\end{array}$ & .303 & .292 & 14.617 \\
\hline
\end{tabular}

a. Predictors: (Constant), Y1

b. Dependent Variable: X

Tabel 7 Determinasi X Terhadap Y2

Model Summary ${ }^{b}$

\begin{tabular}{|c|c|c|c|c|}
\hline Model & $\mathrm{R}$ & $\begin{array}{c}\mathrm{R} \\
\text { Square }\end{array}$ & $\begin{array}{c}\text { Adjusted } \\
\text { R Square }\end{array}$ & Std. Error of the Estimate \\
\hline 1 & $.689^{\mathrm{a}}$ & .519 & .508 & 14.833 \\
\hline
\end{tabular}

a. Predictors: (Constant), Y2

b. Dependent Variable: $\mathrm{X}$ 
Berdasarkan hasil penghitungan menggunakan aplikasi SPSS versi 23.00 diperoleh sebagaimana tabel 1 diketahui nilai koefisien korelasi sebesar 0.760 , harga ini perlu diuji signifikansinya dengan mengkonsulasikan terhadap $r_{\text {tabel. }}$ Harga $r_{\text {tabel }}$ berdasarkan derajat kebebasan $(\mathrm{dk})$ a dalah $\mathrm{N}-1$, yaitu: $31-1=30 . \mathrm{N}=$ 30 untuk taraf signifikansi 0.05 ditemukan sebesar 0.296, dan 0.4093 untuk taraf signifikansi 0.01. Artinya $\mathrm{r}_{\text {hitung }}(0.760)$ adalah signifikan. Berarti pendekatan CTL mempunyai keterkaitan secara signifikan dengan motivasi belajar siswa kelas $\mathrm{VIII}_{3}$ SMPN 1 Sasak Ranah Pasisie.

Kemudian dari tabel 2 diketahui bahwa hasil perhitungan menggunakan aplikasi SPSS versi 23.00 diperoleh nilai koefisien korelasi sebesar 0.753, harga ini perlu diuji signifikansinya dengan mengkonsul-tasikan terhadap $\mathrm{r}_{\text {tabel. }}$. Harga $\mathrm{r}_{\text {tabel }}$ berdasarkan pada tingkat fleksibilitas $(\mathrm{dk})$ yaitu $\mathrm{N}-1$, yaitu $31-1=30 . \mathrm{N}=30$ untuk taraf signifikansi 0.05 ditemukan sebesar 0.296, dan 0.4093 untuk signifikansi 0.01 . Hasilnya, $\mathrm{r}_{\text {hitung }}(0.753)>\mathrm{r}_{\text {tabel }}(0.296)$ pada signifikansi 0.05 , dan $r_{\text {hitung }}(0.753)>r_{\text {tabel }}(0.4093)$ pada signifikansi 0.01. Artinya $r_{h i t u n g}(0.760)$ adalah signifikan. Berarti pendekatan CTL berkorelasi secara signifikan dengan prestasi belajar peserta didik kelas VIII 3 SMP Negeri 1 Sasak Ranah Pasisie.

Tabel 3 menampilkan hasil penghitungan menggunakan aplikasi SPSS versi 23.00 diperoleh nilai koefisien korelasi sebesar 0.870 , harga ini perlu diuji signifikansinya dengan mengkonsultasikan terhadap $r_{\text {tabel }}$. Harga $r_{\text {tabel }}$ berdasarkan tingkat fleksibilitas (dk) yang besarnya adalah $\mathrm{N}-1$, yaitu $31-1=30 . \mathrm{N}=30$ untuk signifikansi 0.05 ditemukan sebesar 0.296, dan 0.4093 untuk taraf signifikansi 0.01. Hasilnya, $r_{\text {hitung }}(0.870)>r_{\text {tabel }}(0.296)$ pada signifikansi 0.05 , dan $r_{\text {hitung }}$ $(0.870)>r_{\text {tabel }}(0,4093)$ pada signifikansi 0.01. Artinya $r_{\text {hitung }}(0.870)$ adalah signifikan. Berarti motivasi belajar memiliki hubungan yang kuat dengan prestasi belajar peserta didik di Kelas VIII 3 SMPN 1 Sasak Ranah Pasisie.

Untuk mengetahui pengaruh dari variabel terikat terhadap variabel bebas maka peneliti melakukan Uji F: 1) $F_{\text {hitung }}: F_{\text {tabel }}$, dengan criteria jika $F_{\text {hitung }}$ lebih besar dari $\mathrm{F}_{\text {tabel }}$ maka itu artinya variabel bebas mempengaruhi variabel terikat secara signifikan. Namun apabila $F_{\text {hitung }}$ lebih kecil dari $F_{\text {tabel }}$ maka hal itu berarti tidak terdapat pengaruh dari variabel bebas ke variabel terikat. Adapun perolehan nilai $F_{\text {tabel }}$ ialah dengan menggunakan rumus $\mathrm{Df}=\mathrm{N}-1$, maka $31-1=30$. 
Ditemukan 4.171 pada probabilitas $5 \%$ dan 7.56 pada probabilitas $1 \%$. Selanjutnya menguji perbandingan signifikansi yang terdapat di table Anova, apabila signifikansi kecil dari 0.005 , hal itu menunjukkan variabel bebas berpengaruh secara signifikan terhadap variabel terikat. Namun jika signifikansi $>0.005$, hal itu berarti tidak terdapat pengaruh variabel independen terhadap variabel dependen

Sesuai dengan hasil analisis data yang terdapat pada table 4 diketahui hasil uji $\mathrm{F}$ antar variable $\mathrm{X}$ dan $\mathrm{Y} 1$ ialah dengan nilai $\mathrm{F}_{\text {hitung }} 54.442$, dan $\mathrm{F}_{\text {tabel }} 4.171$ pada probabilitas 0.05 , dan 7.56 pada probabilitas 0.01 , maka kesimpulannya adalah: a) 54.442>4.171, data ini memiliki arti bahwa pengaruh variabel independen mempengaruhi variable terikat pada taraf $5 \%$. dan, b) 54.442>7.56, perolahan skor ini memiliki arti keterpengaruhan dari variabel bebas kepada variabel terikat ialah sebesar $1 \%$.

Data tersebut menunjukkan signifikan $0.000<0.05$, artinya variabel-variabel dependen secara signifikan sama-sama dipengaruhi variable independen.

Selanjutnya Uji $\mathrm{F}$ terhadap variabel $\mathrm{X}$ dan $\mathrm{Y} 2$ juga dilakukan dengan: 1) melihat perbandingan nilai yang terdapat pada $\mathrm{F}_{\text {tabel, }}$ dengan kriteria apabila $F_{\text {hitung }}>F_{\text {tabel }}$ maka variabel bebas memiliki pengaruh yang besar terhadap variabel terikat. Tetapi jika $F_{\text {hitung }}<F_{\text {tabel }}$ data itu menunjukkan bahwa variable terikat secara signifikan tidak mempengaruhi variabel terikat. $\mathrm{F}$ table diperoleh dengan rumus $\mathrm{Df}=\mathrm{N}-1$, maka $31-1=30$. Ditemukan 4.171 pada probabilitas $5 \%$ dan 7.56 pada probabilitas $1 \%$. 2) apabila diketahui hasil perbandingan dengan taraf signifikasi yang ada pada tabel Anova dengan tingkat $<0.005$ perolehan data ini memiliki arti bahwa variabel bebas memberikan pengaruh yang tinggi terhadap variabel terikat. Akan tetapi jika signifikans >0.005 artinya vaiabel dependen tidak terpengaruh oleh variabel independen.

Berdasarkan uji F sebagaimana pada tabel 5 diketahui: 1) Nilai $F_{\text {hitung }} 50.10$ dan $\mathrm{F}_{\text {tabel }}$ 4.171, pada taraf $5 \%$. dan, 7.56 taraf $1 \%$. Dapat disimpulkan bahwa: a) 50.102>4.71, berarti independent variable memiliki pengaruh yang signifikan kepada dependent variable pada taraf 0.05 dan, b) 50.102>7.56. artinya independent variable mempengaruhi dependent variable secara signifikan pada taraf $1 \%$. 
Dengan demikian signifikan $0.000<0.05$, artinya independen variabel secara signifikan mempengaruhi dependent variable.

Analisis selanjutnya adalah uji determinasi. Untuk menentukan besarnya variasi suatu variable terhadap variasi variabel yang lain digunakan koefisien determinasi. Sehingga akan diketahui seberapa besar hubungan dari beberapa variable.

Dalam rangka mendapatkan pengaruh variabel bebas terhadap variabel terikat dapat dilakukan dengan menggunakan analisis determinasi dalam regresi linear. Besarnya porsentase pengaruh variasi variable bebas $\mathrm{X}$ untuk menjelaskan variasi variable terikat ditunjukkan oleh koefisien determinasi. Jika $\mathrm{r} 2=0$, hal ini variabel independent sama sekali tidak memberikan pengaruh terhadap variabel dependen. Jika $\mathrm{r} 2=1$, hal ini berarti variasi variabel independent mempengaruhi variabel terikat.

Hasil yang didapat dari Uji determinasi sebagaimana table 6 memperlihatkan, nilai R Square adalah 0.303, dapat diketahui, pendekatan CTL (X) berpengaruh $30.3 \%$ terhadap motivasi belajar siswa.

Sementara Uji determinasi anatar variable X terhadap Y2 menunjukkan bahwa nilai R Square adalah 0.509, dapat diketahui bahwa pendekatan CTL (X) berpengaruh $50.9 \%$ terhadap prestasi belajar Siswa.

Dari hasil analisis data yang dilakukan dapat dikatakan bahwa hasil penelitian ini menguatkan pendapat dan hasil penelitian terdahulu yang menyimpulkan bahwa penggunaan metode tertentu akan memberikan dampak terhadap hasil belajar (Bansal, Ahmad, \& Pandey, 2020). Secara khusus hasil penelitian ini menguatkan temuan Danis dkk yang menyimpulkan bahwa pendekatan CTL mempengaruhi terhadap hasil belajar (Danis, Bungana, Sri, \& Milfayetty, 2017). Di samping itu, penelitian ini juga menguatkan hasil penelitian Kosassy dkk (Kosassy et al., 2018) yang menyatakan pembelajaran yang kontekstual dengan kehidupan siswa memberikan dampak terhadap hasil belajar.

\section{KESIMPULAN}

Berdasarkan paparan hasil dan pembahasan disimpulkan bahwa: pertama, pendekatan CTL memiliki hubungan yang signifikan terhadap motivasi belajar, 
pernyataan ini didasarkan pada nilai $r_{\text {hitung }}(0.760)>r_{\text {tabel }}(0.296)$ pada signifikansi 0.05 dan $r_{\text {hitung }}(0.760)>r_{\text {tabel }}(0.4093)$ pada signifikansi 0.01 , kemudian uji regresi sebesar 30\% dengan Rsquare adalah 0.3.3. kedua, terdapat pengaruh pendekatan CTL terhadap hasil belajar terlihat dari nilai $r_{\text {hitung }}(0.753)>r_{\text {tabel }}(0.296)$ pada signifikansi 0.05 dan $r_{\text {hitung }}(0.753)>r_{\text {tabel }}(0.4093)$ pada signifikansi 0.01, kemudian uji regresi sebesar 51.9\% dengan R Square adalah 0.519 .

\section{DAFTAR PUSTAKA}

Asvio, N., Arpinus, \& Suharmon. (2017). The Influence of Learning Motivation and Learning Environment on Undergraduate Students' Learning Achievement of Management of Islamic Education, Study Program of IAIN Batusangkar. Noble International Journal of Social Science Research, 2(2), 16-31.

Bansal, S., Ahmad, K., \& Pandey, J. (2020). Effects of a Flipped Classroom Approach on Learning Outcomes of Higher and Lower Performing Medical Students: A New Insight. Adv. Educ Res Eval, 1(1), 23-31. https://doi.org/10.25082/AERE.2020.01.005

Danis, A., Bungana, R., Sri, B. P., \& Milfayetty, S. (2017). The Effect of Contextual Teaching and Learning (CTL) and Motivation to Students' Achievement in Learning Civics in Grade VII SMP Imelda Medan. IOSR Journal of Research \& Method in Education (IOSR-JRME), 7(6), 24-33. https://doi.org/10.9790/7388-0706012433

Hakim, R., \& Ritonga, M. (2018). A Study of Religion Education Method With Multicultural Insight. In International Seminar on Islamic Education (ISIE 2018) Faculty of Islamic Religion, Universitas Muhammadiyah Ponorogo, July 07th, 2018 (pp. 81-97).

Haryanto, P. C., \& Arty, I. S. (2019). The Application of Contextual Teaching and Learning in Natural Science to Improve Student's HOTS and Self-efficacy. In Journal of Physics: Conference Series (pp. 1-8). https://doi.org/10.1088/17426596/1233/1/012106

Kosassy, S. O., Gistituati, N., Jama, J., \& Montessori, M. (2018). The Implementation of Contextual Learning Approach in e-Learning Based on Weblog Toward Students Learning Achievements. Journal of Counseling and Educational Technology, 1(2), 59-64.

Manangkari, I. (2018). Implementing Contextual Teaching and Learning to Improve Vocabulary and to raise Students Learning Motivation of the Seventh Grade Students at MTs Negeri 1 Banggai. Journal of Foreign Language and Educational Research, 1(2), 17-24.

Munawaroh, \& Setyani, N. S. (2015). The Development of Learning Model With The Approach Of CTL (Contextual Teaching And Learning) Through The Method Of Apbl (Authentic Problem Based Learning) To The Subject Of Entrepreneurship. IOSR Journal of Research \& Method in Education, 5(3), 8695. https://doi.org/10.9790/7388-05338695

Nurjanah, E., \& Sofiawati, E. T. (2019). Implementation of Education Quality Improvement in Primary Schools Judging From Teacher Competency Test in Sukabumi Regency. International Journal for Educational and Vocational Studies, 1(7), 773-776. 
Panggabean, M. S., \& Himawan, K. K. (2016). The Development of Indonesian Teacher Competence Questionnaire. Journal of Educational, Health and Community Psychology, 5(2), 1-15.

Raman, M. R. A., Haniffa, M. A. B., \& Haron, S. D. M. A. B. (2018). The Drill and Practice Application in Teaching Science for Lower Secondary Students. International Journal of Education, Psychology and Counseling, 3(7), 100108.

Riswanto, A., \& Aryani, S. (2017). Learning Motivation and Student Achievement: Description Analysis and Relationships Both. Couns-Edu: The International Journal of Counseling and Education, 2(1), 42-47. https://doi.org/10.23916/002017026010

Sari, W. K., \& Wilujeng. (2020). Education Change in The Industry 4.0: Candidate science Teacher Perspective. In The 5th International Seminar on Science Education: Journal of Physics: Conference Series (pp. 1-7). https://doi.org/10.1088/1742-6596/1440/1/012090

Sen, H. S. (2013). The Attitudes of University Students Towards Learning. Procedia Social and Behavioral Sciences, 83, 947-953. https://doi.org/10.1016/j.sbspro.2013.06.177

Sufianto. (2019). The Effect of Contextual Teaching And Learning ( CTL ) Learning Model on The Ability Of Concept Understanding Class VII Students of SMP 16, Kota Bengkulu. Jurnal Pendidikan Matematika Raflesia, 4(1), 1928.

Wong, L. T., \& Dubey-Jhaveri, A. (2016). English Language Education in a Global World Practice, Issues and Challenges. New York: Nova Science Publishning, Inc. https://doi.org/10.13140/RG.2.1.2241.7047

Zamroni. (2019). Innovation of Learning Management in Madrasah Level. Dinamika Ilmu, 19(2), 337-349. 